\title{
Strategies for Functional Community- Based Instruction and Inclusion for Children with Mental Retardation
}

Joni Beck
$\begin{aligned} & \text { any teachers of ele- } \\ & \text { mentary-aged stu- } \\ & \text { dents with mental }\end{aligned}$ retardation are attempting to provide learning experiences in the community to prepare them for a better quality of life as adults. At the same time, they are attempting to support growing relationships between these students and their nondisabled peers through general education integration. Yet, these two important areas can conflict with each other (Ford \& Black, 1989). Increasingsintegrated time with peers while also teaching functional skills in the community can present conflicts of time and instructional priorities, or it can present a golden opportunity for collaborative planning between gemeral and special education teachers as well as for inclusive education.

Federal policies with respect to special education are implemented by states that render themselves accountable to the U.S. Department of Education in return for fiscal and technical support. School districts replicate this pattern, complying with state mandates that typically parallel federal legislation such as the Individuals with Disabilities Education Act (IDEA, P.L. 101-476).

Local policies attuned to state mandates and field-based țends are usually developed and then used as evidence of compliance. However, it is ultimately teachers and instructional leaders who must implement these policies in their school bullings and demonstrate compliance at the service delivery level rather than the policy level. In our case, we were responsible for creating practical ways to meet the challenge of two seemingly paradoxical trends: func-
- Earle Knowlton 


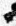

contemplated teaching: Will I need it when I'm 21 (Burns \& Shipstead, 1989)? All of our curricular decisions hinge on the answer to this question. Young children with mental retardation cannot answer this question for themselves yet, so families and teachers must answer it for them, continuously looking ahead to the future for each child.

Ensuring that functional outcomes remain part of a student's individualized education program (IEP) is of utmost importance. In the past, curriculum in self-contained classrooms for students with mental retardation primarily involved adapting and modifying grade level skills. Based on Brolin's (1992) framework, Burns and Shipstead (1989) developed and implemented a life skills program oriented to adult outcomes for children in inclusive settings starting at 5 years of age. For example, in the general education setting there are some naturally occurring life skills that relate to skills needed by adults. For example, coming to the circle on time in kindergarten might relate to getting to work on time as an adult. With a commitment for all children to become successful adults, professionals can collaborate and plan funçtional lessons that integrate curricular content in areas such as math and social studies as well.

a

\section{Functional Curricula in General Education}

The cooperative teaching planner (Figure 1) reflects 1 of 6 weeks of lessons combining first-grade social studies and math skills that are taught in a functional format for children in both general and special education. The teachers, a first-grade teacher and a teacher of students with mental retardation, use a predesigned resource area assthe main setting for the lessons, although some lessons occur in the first grade classroom. Through one series of ressons, the children operated a store at school. During different time periods, the expertise and cooperation of the learning disabilities teacher and the speech therapist were used to reinforce skills needed to run the store. First grade social studies concentrated on economics and involved concepts of needs, wants, supply, and demand. The Brolin (1992) model provided a concise reminder of the life skills outcomes on which the lessons were focused.

One of the several things we learned is that team teaching is fun: It is enjoyable to collaborate with another adult in lesson plaaning and to share responsibilities and resources. Staff relations are enhariced by working together and sharing information and talents. In addition, the repetition and functional aspects of the lesson design that are so much a part of the special education curriculum also are instructionally and socially sound for general education peers of the appropriate age, Recently, Algozzine and Audette (1992) advocated a more functhol perspective on curriculum and instruction for general education students based on this idea. Thousand Lnd Villa (1991) also suggested that curficula and methods traditionally geared to the needs of youngsters with disabilities "have the potential of greatly enhancing the preparedness of other students for the $6 \mathrm{~m}$ plex adult life of the future" (p. 557).YThe peer coaching employed in the lessons is also beneficial for all students. The students learn a lot about each otker, discovering that they are more alike than different.

\section{Rationale for Community-Based Integratèd Instruction (EBII)}

Experiences in community settings generate opportunities for all students to draw on their skills and use problemsolving strategies with guidance as needed from the teacher. The general education curriculum divides information into sybject areas, but in the real world,students must combine skills and knowledge and use them in functional ways. Occasions for spontaneous problem-solving arise in real-life situations, as opposed to simulated situations in a classroom. Community-based lessons allow teachers to work on a variety of objectives at varying levels and make learning interesting for all students (Ford \& Davern, 1989).

Community-based instruction is an important part of the curriculum. Experiences in the community ape Imperative for students with mental retardation because they provide the opportunity to learn the kills these students will need as actalk. The principle of normalization (Wolfensberger, 1972) provides the philosophical basis for community-based instruction, stressing environments and circumstances that are as culturally normal as possible to enhance behaviors that are as culturally normal as possible (Schutz, Williams, Salce-Iverson, \& Duncan, 1984). Teaching the skills needed for daily living in the community operationalizes the concept of normalization (Martin, 1988). If students with mental rétardation are nót/given opportunities to practice skills in the environments in which the skills are to be used, the chances that those skills will generalize from simulated learning in the classroom to the realworld environment are minimal (Falvey, 1989).

\section{Implementing CBII}

The purpose of the CBII program is to combine integration and communitybased instruction to accomplish the fol- lowing three goals:

1. To providedearning opportunities in the community for students with mental retardation with nondisabled peers as models.

2. To provide opportunities for the application of skills in the community for all students at their individual levels of ability.

3. To develop a teaching partnership between special and general education teachers, with general education teachers teaching students integrated into their classrooms and the special education teachers teaching - students in community settings.

Collaboration between general and special, education teachers to set objectives for community-based instruction results in their focusing on the curricu- 


\section{Figure 1. Cooperative Teaching Planner}

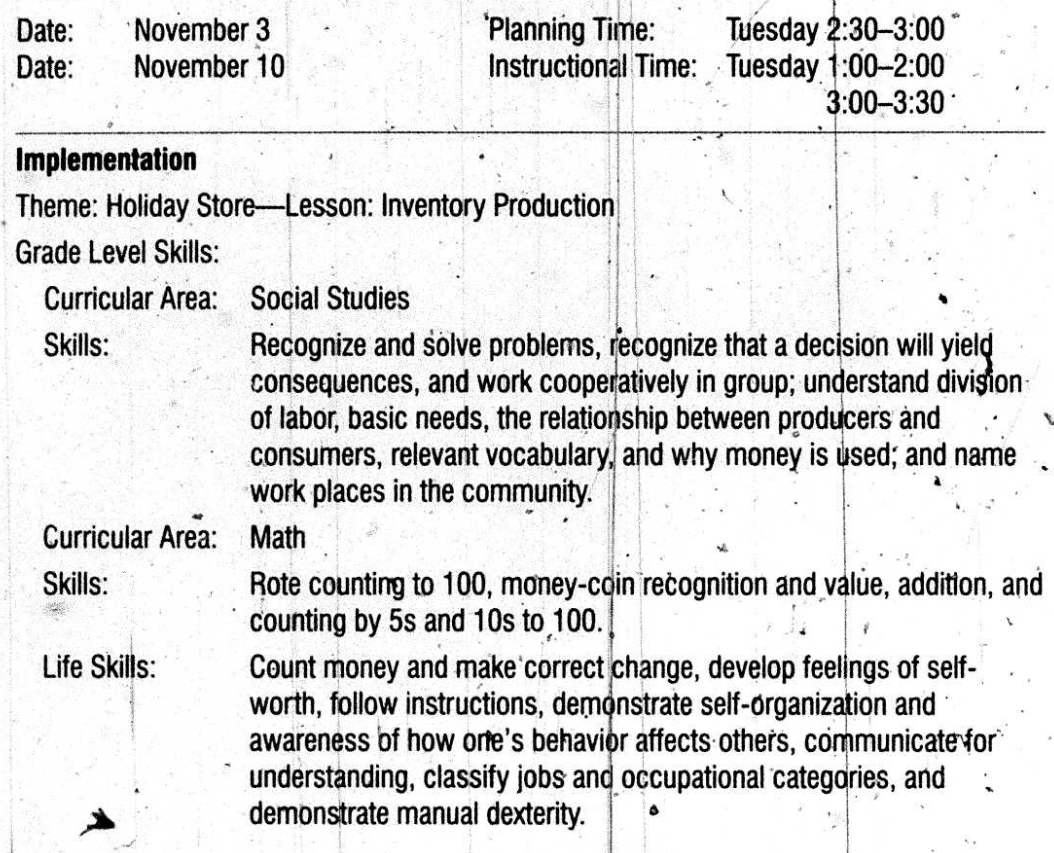

\section{Lesson}

Set

Objective

Instructional Input

Guided Practice

Check for Understanding

Model

Independent Practice

Closure
Review èconomics terminology.

Discuss store format. Look at timeline.

Students will produce items for actual retail sale by, working cooperatively (group/individual as needed) and demonstrate an understanding of economic concepts.

What do we need to know about? (Mơney)

\section{Rote counting to, 100 (1s, 5s, 10s} Money recognition and value

Show set up for today's production (products and worker assignment)

Students produce.

'Review what progress was made today. Check workers' . happiness with their jobs. Review students' understanding that their production produced projects to sell and make a profit.
'Overt activities to assess level of understanding

\section{Materials Needed}

Calendar with store timeline

\section{Overhead}

Transparent coins

Individual coin containers

Chart 1-100

Room arranged for production

Materials for gift bags, tags,

Earrings, necklaces, recipe cards lar goals and objectives of both and encourages general education teachers to view the community as a means of instruction, rather than simply a field trip site. Objectives can be created for small groups of students at their individual ability levels. A limit of two to five students per trip optimizes instruction.

The following is an example of the successful use of CBII. A trip to the grocery store focused on the following objectives: (a) read street crossing signs/signals and information signs; (b) demonstrate safe street-crossing behavior; (c) read a list; (d) select item s needed; (e) compare prices of similar items; (f) count money to make a purchase; and (g) demonstrate appropriate purchasing behaviors such as waiting in line, handfling money; waiting for change, and carrying purchases. These objectives were task analyzed and serially or functionally chained according to. the needs of the individual students.

The collaboration for CBII was initiated through a letter describing CBII that was distributed to the second, third, and fourth grade general education teachers by the special education teacher serving students with mental retardation at those grade levels. The letter explained the CBII program, offering the teachers an opportunily to participate. All seven of the teachers at these grade levels responded with interest. A letter also was sent to parents, and it included a permission slip for students to participate in CBII. Parents were encouraged to call the speciateducation teacher if they had questions about the program. Approximately 75 'second, third, and fourth 'graders volunteered to participate.

Trips were arranged by the special education teacher in collaboration with the general education teachers. Most - community-based instruction involved small groups of two to five students from the same grade level. The students with mental retardation from that grade level always participated, and the other students were rotated so that all would have a furn. Prior to each trip, all students met briefly with the special education teacher to discuss the purpose ' and each student's objective(s). 
Qbjectives for the students with mental retardation were develaped on the basis of Brolin's (1992) Life Centered Career Education (LCCE) model. An examination of the functional skills outlined by Brolin reveals a number of areas that also are taught in the elementary general education curriculum for nondisabled students; examples are time, money, seasons (appropriate clothing), and health (body care). When general education and special education teachers collaborate to plan age-appropriate lessons, these functional skills can be incorporated into lessons and units. This functional curriculum model focuses on skills needed to be independent adults. Objectives for stúdents' IEPs were based on these functional skills. These same skills were the focus of objectives carried out in community settings. Another concept was also embraced in planning for CBII: The most effective programs for students with disabilities are characterized by integration of general and special education, classroom and communitybased instruction, and use of functional curriculum (Boyer-Stephens \& Kearns, 1988).

Objectives for general education students were developed prior to each trip by the general and special education teachers. A grocery store and a fast-food restaurant within walking distance of the school were the most frequently used sites. Instruction at the grocery store was followed by lunch or snack preparation by all students involved using the items that were purchased. The specialleducation teacher supervised these activities in her classrodm.

- Most community-based instruction takes approximately 30 to 40 minutes, and follow-up activities can extend another half hour. If general education students miss"assignments while participating in CBII, the special education teacher-arranges assistance for them in completing their work either before or after trips. Paraprofessionals remain with students who are not participating in CBII that day, working on preplanned activities. Another special edücation teacher in the building is designated as the teacher in charge while the teacher participating in CBII is out of the building.

Our collaborative program included two CBII activities that were all-da), large-group activities involving up to 18 students. These were trips to a zoo and a farm. Objectives were less community skill specific for each student and focused more on socialization skill op̀portunities and activities. Prior to these trips, general education students visited the special education classroom and; together with the studẹts with mental retardation, participated in readiness activities related to the themes of the community-based instruction This provided the students with an opportunity to become acquainted with each other and the staff prior to the allday trips.

Cost may be a concern for educators interested in develöping and implementing a CBII program. Most funds for our CBII program were provided through a fundraising project. Pingon badges with Valentine themes were sold by students with mental retardation to the school's student body prior to Valentine's Day. With special education funds providing transportation for some community instruction and for some gro- cery items, we had a sufficient dmount to plan andimplement our program.

\section{Benefits of CBII}

Although we have not formally evaluated CBII, we have observed the following consistent effects of the program:

1. A substantial number of nondisabled students demonstrated motivation to participate in CBII activities, and associating with peers with mental retardation became a preferred activity of choice even more frequently after the program started operating.

2. Nondisabled students were observed interacting positively and more frequently with their peers with mental retardation following a community-based instruction trip.

3. Nondisabled students who were originally unsure about participating expressed interest after hearing about CBII from their classmates.

4. Positive responses were received from parents of students with and without disabilities.

5. General education teachers frequently ásked students who had par-

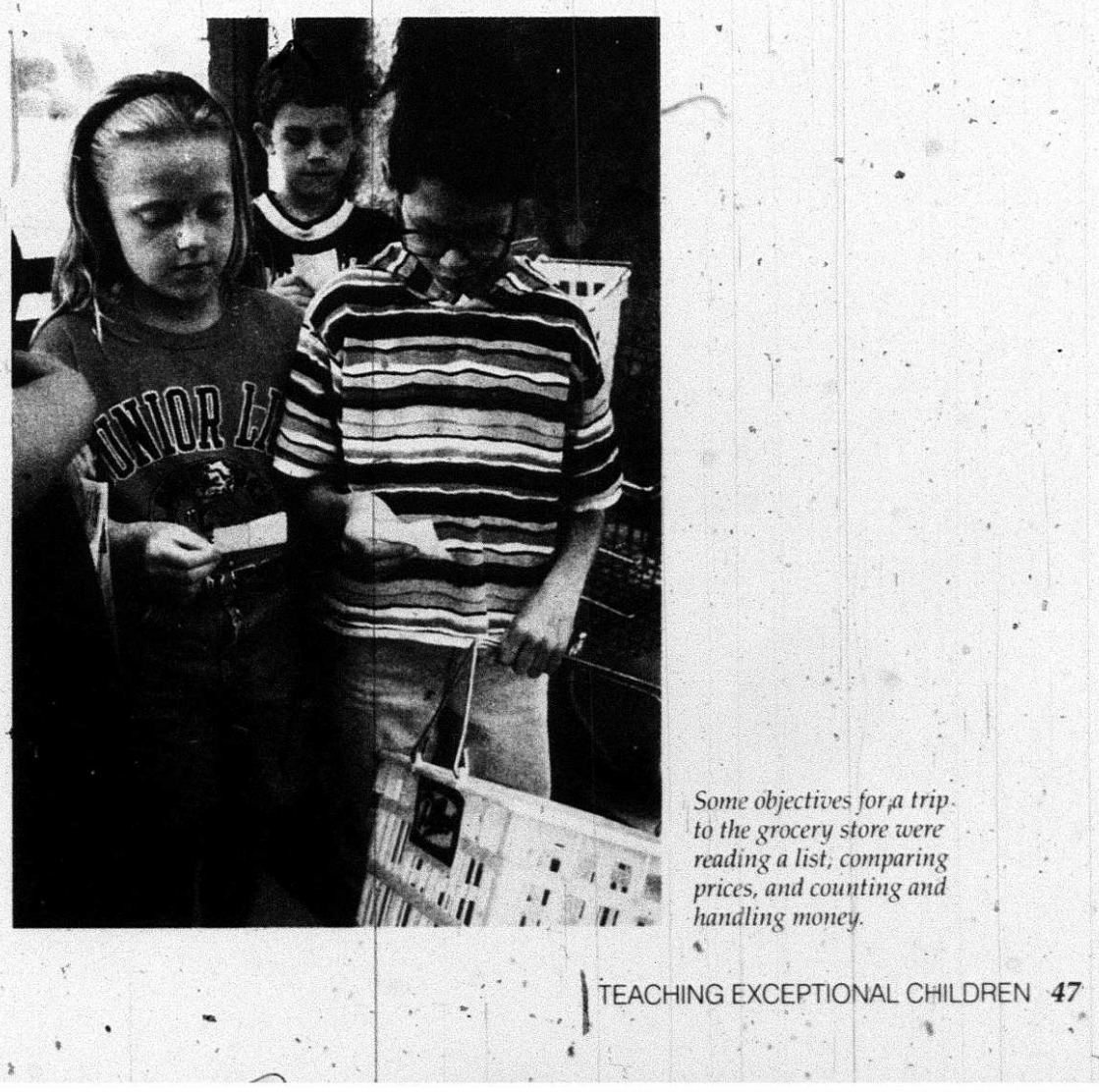


ticipated in CBII to share their experiences with classmates.

6. Teachers spontaneously 'expressed enthusiasm for and interest in continuing $\mathrm{CBH}$ during the next school year.

7. General education students became more responsive to students with mental retardation and their teachers, interacting in the halls and during lunch and recesses and involving them more in the life of the school.

\section{Instructional Lęadership}

Administrative support for communitybased instruction is a key to success, The principal of the school has a crucial rele to play in providing the encouragement and expectation that functional skills will be part of the curriculum forall students. This is achieved with the realization that students with mental retardation will need more time and repetition to acquire and maintain the skills than will most other students.

- Some ways in which the principal can provide the impetus for the teaching of functional skills are listed here:

- Be a catalyst for inclusion. CBII will not happen inless the principal takes a leadership role.

- Provide staff development activities regarding functional skills and how they are related to the general education curriculum.

- Demonstratè acceptance of students with mental retardation in the school and in classrooms by visiting the classrooms, discussing the progress of students with teachers, and taking

time to talk with the students about what they are doing.

1. Find ways for teachers to have time to collaborate and plan together. Examples include providing release time by tẹaching classes, departmentalizing, combining classes periodically, scheduling assemblies on a regular basis, and adding minutes to the school day to provide for early dismissal days.

- Explain the benefits of the program to general education parents as well as special education parents.
- Speak to community groups to prot mote acceptance of persons with disabilities.

- Persorally praise teachers and send notes of appreciation for their efforts.

- Create fun, diversionary activities to offset the hard work and strest associated with the teaching profession. Each year we have Sècret Pal Week. Each staff member/draws the name of another staff meniber for whom she or he will be a secret pal for a week. Each pal buys his or her partner trinkets (one per day) that pro-" vide hints as to the secret pal's identity: On Friday, the secret pals' reveal who they are. Although they may seem silly, such diversions build $a$ sense of being part of a team and set the stage for meaningful professional dialogue and collaboration.

\section{Conclusion}

Learning functional skills within community settings helps students with mental retardation increase their odds. for achieving maximum independence and a kigh quality of life. Programs that teadh those skills also help general education students who may not be taught at home and students who have learning difficulties but do not qualify for special education services. In fact, all students can benefit from such instruction. Given administrative support and adequate preparation of staff, students, and parents, the inclusion process for students with mental retardation and their general education peers can be extended beyond the school and into the community. Implementation of these programs during the school years proyides all students with opportunities. to reach their potential as independent adults and to become aware and accepting of individual differences within their school and community.

\section{References}

Algoonine, B., \& Audette, B. (1992). Free and appropriate educatio for all students. Total quality and the transformation of American public education. Remetial and Special Education, 13(6), 8-18. Beck, J. (1991). Community-bised integrated instruction. Unpublished master's project, University of Kansas, Lawrence.

Boyer-Stephens; A., \& Kearns, D. (1988, Fall). Functional curriculum for transition. The Jotirnal, $p$. 13.

Broers; J. (1992). Teaehing functional skills within general education settings. Unpublished manuscript. Lawrence, KSi Lawrence Unified School,District.

Broers, J., Bukaty, G., Hogue, E., \& Shipstead, J. (1993, February). Days of their lize's. Paper presented at the meeting of the National Association of Elementary Principals, Kansas Citý, MO.

Brolin, D. E. (1992). Life centered career eduation: A competency based appreach. Reston, VA: The Council for Exceptional Children.

Burns, N., \& Shipstead, J. (1989). Commnunity reterenced life skills curriculam for slementary school. children with special nects. Unpublished manuscript. Lawrence: University of Kansas, Department of Special Education.

Falvey, M. (1989). Community-lnsed curriculum (2nd ed.). Baltîmore: Paul H. Brookes

Ford, A., \& Black, J. (1989). The community-referenced curriculum for students with moderate and severe disabilities. In D: Biklen, D. Ferguson, \& A. Ford (Eds.), Eighty-cighth yearbook of the National Society for the Study of Edacation, il (pp. 141-167). Thicago: University of Chicago Press.

Ford, A., \& Davern, L. (1989). Moving forward with scheol integration: Strategies for involving students with severe handicaps in the life of the school. In R. Gaylord-Ross (Ed.), Integration strategies for students with secer handicaps (pp. 11-20). Baltimore: Paul H. Brookes.

Martin, J. (1988). Providing training in community and domestic skills. In L. Heal, J, Haney, \& A. Dovak Amado (Eds.), Integration of dryolozmentally disabled indieviduals into the cominguity (pp. 169-170). Baltimore: Paul H. Brookes.

Schutz, R., Williams, W., Salce-Iverson, G., \& Duncan, D. (1984) . Social integration of severely handicapped students. In N. Certo, N. Haring, \& R. York (Eds.), Public school integration of seterely handicapped stutents (pp. 15-20). ' Baltigore: Paul H. Brookes.

Shipstead, J. (1992). Teaching children to be atults: $A$ practitioner's viewpoint. Unpublished master's project, University of Kansas, Lawrence.

Thousand, L, \& Villa, R. (1991). A futuristic fiew of the REI: A response to Jenkins, Pious, and Jew'ell. Exceptional Children, 57, 556-562.

Wolfensberger, W.(1972). The principles of normalization in humaj services. Toronto: National Institute on Mental Retardation.

Joni Beck (CEC Kansas Fog ation), Interrelated Resource Teacher; Janet Broers, Principal: Elonda Hogue, First Grade Teacher; and Jacque Shipstead (CEC Chäter \# 665), Interrelitwed Resource Teacher, Cordly Elementary School, Lawrence, Kansas. Earle Knowlton (CEC Chapter \#665), Associate Professor and Coordinator, Mental Retardation Program Area, Department of Special Education thitiersity of Kansas, Lawence.

Copyright 1993 CEC. 